\title{
EXPLORING PRESCHOOL CHILDREN'S USER EXPERIENCE IN USING FREE-ROTATE GESTURES ON TOUCHSCREEN DESIGN: THE CASE OF LEARNING SHAPES
}

\author{
Fadhlina Mohd Razali, Nor Azah Abdul Aziz, Siti Aisyah Salim, Roznim \\ Mohamad Rasli and Nur Farah Zulkefly \\ Faculty of Art, Computing and Creative Industry, Sultan Idris Education University, \\ Tanjung Malim, Perak, Malaysia
}

\begin{abstract}
Free-rotate gestures enable users to rotate objects on the touchscreen interactively. Therefore, this study was carried out to explore the user experience of preschool children when using free rotate gestures. Five attributes of user experience, namely attractiveness, perspicuity, efficiency, dependability, and stimulation, were examined. The sample of this study consisted of 10 children, aged 5 and 6 years old were instructed to learn shapes by using a mobile application called "Mari Belajar Bentuk". They were required to use their fingers to touch and rotate several shapes. The analysis showed that all attributes of such construct were deemed high. As conclusion, the overall finding strongly suggests that free rotate gestures on multi-touch screen design can enhance preschool children's user experience. With high user experience, young children can experience engaging and meaningful learning. Consequently, future research should explore this gesture as it can make young children become highly motivated in learning.
\end{abstract}

\section{KEYWORDS}

Free-rotate gestures, multi-touch gestures, preschool children, user experience

\section{INTRODUCTION}

Nowadays, numerous technologies with exceptional features and capabilities are available, which have radically transformed the training and educational landscapes. For example, multi-touch technologies are being used to provide an affectional learning platform for students not only in tertiary education but also in early childhood education [1]. Essentially, multi-touch technology is defined as the method of input that allows devices to recognise and respond to the touch of two or more fingers at multiple locations simultaneously on a touchscreen [2]. In this regard, a majority of devices that are based on touch screen technologies, such as iPads, tablets, and smartphones, have interfaces that support multi-touch interaction. Through this interaction, users can easily gain direct access to digital contents by just touching such interfaces with their fingers without using any conventional input devices [3]. Naturally, such an interaction through multiple-touch gestures is captivating and appealing to users, especially to young children who are naturally drawn to new technologies, which will have a profound effect on their learning [4]. Free rotate gestures have been widely used in the multi-touch screen design, but in-depth research of such gestures is seriously lacking [5]. In essence, free rotate gestures require users to use at least two of their fingers to make contact with a touchscreen to perform rotation gestures [6].

In this information-driven era, children are growing up with a dazzling array of technologies. Arguably, young children are able to use computer applications more articulately than they can read and write [7], and such ability will have several implications on their learning. Nowadays, children are so familiar with a host of computer devices with multi-touch screen design, enabling 
them to use various digital applications with ease and comfort. With such screen design, user interaction becomes highly interactive and spontaneous, which helps users to perform tasks more effectively and efficiently. Therefore, it is not surprising to notice that multi-touch screen design has been used in many learning tools to improve student learning in a number of disciplines, such as in the learning of geometrical shapes among kindergarteners. In fact, in Malaysia's preschool curriculum, the topic of shapes is one of the core topics of science, mathematics, and language. The findings of recent studies suggest that learning shapes using touch gestures is not only easy but also engaging, the impact of which can help reinforce preschool children' understanding of two-dimensional structures. Nevertheless, the above researchers did not use any specific gestures, such as free rotate gestures, in their studies involving preschool children [8]. Therefore, the researchers carried out this study with the main aim to investigate the user experience of preschool children in using free rotate hand gestures on a multi-touch screen in learning geometrical shapes.

\section{LITERATURE REVIEW}

With increasing advancement in mobile technology, many mobile devices, notably iPads, have become a potent tool that virtually affects almost all aspects of the people's lives, particularly in education, among others. For example, iPads have been used pervasively in many schools throughout the world, especially in developed nations, to engage students in learning and training activities $[9,10]$. In fact, such technological tools are being continually harnessed to help children learn with greater enthusiasm and interest. Nonetheless, the pervasive use of these tools in the learning domain has raised some concerns or issues among parents and teachers. As such, several studies have been carried out to address some of these issues. For example, a study by Genc [11] showed that parents' sensitivities toward technology use of their children varied substantially. In his study, the percentages of parents expressing their disapproval and approval of the use of such tools by their children were $46.88 \%$ and $26.56 \%$, respectively. Only $26.88 \%$ of the parents indicated that they neither agreed nor disagreed. For parents with positive opinions, they believed that these technological tools could help develop or improve their children's motor and cognitive skills, technological knowledge, and visual memory. In contrast, those expressing negative opinions believed that reliance on such tools would cause many physical and mental problems on the long run. Interestingly, research by Blackwell [12] showed a majority of parents had strong approval of the use of tablets or iPads as a powerful learning aid that could assist their children in learning, citing that such tools had inherent capability to provide learning opportunities anywhere, anytime. Of late, such mobile devices have been widely used in early childhood education to assist teachers to carry out their teaching tasks according to the prescribed requirements of the curriculum $[4,12]$.

Shapes are one of the topics of early childhood education that preschool children must learn to identify the names of common two-dimensional shapes, such as circles, squares, triangles, ovals, and rectangles. A number of teaching strategies and activities have been developed to help students to recognize and compare such shapes [13]. For example, one of the strategies used entails introducing the children the various kinds of triangles, such as equilateral, isosceles, and scalene triangles. Then, students need to compare such shapes by examining the different sizes of the shapes. Subsequently, students have to explain the differences between two-dimensional (flat) shapes and three-dimensional (solid) shapes. In this respect, preschool children can improve their understanding of geometry by engaging them in activities in which they learn to classify various shapes based on different angles and three-dimensional objects [14]. Helping students to focus on the above tasks entails asking them the right questions, such as "How a book and a piece of paper are similar?" and "How do they differ from one another?

Multi-touch gestures afforded by the touch-screen technology are a new method of interaction that is widely used in many applications running on mobile devices, such as hand phones and 
tablets. In fact, multi-touch gestures are also a means to provide input to the touch screen using two or more fingers simultaneously. In this study, preschool children, aged 5 and 6 , were selected as the research subjects, given that they would be able to use a mobile application by using their two fingers to touch the touch-screen of a mobile device quite naturally. The same would not be true if younger children were chosen, because they would most likely touch the screen with both hands. Several recent studies have been carried out to examine the impacts of different multifinger and hand gestures, including rotation, on a multi-touch display [15, 16]. According to Hoggan et al. [5], rotation is defined as the radial motion of the thumb and the index finger around a fixed point as shown in Figure 1. The researchers observed that such two-finger gestures could generate high levels of muscle activations. Moreover, they strongly recommended that (based on the guidelines of Windows 8 and Apple iOS) 90-degree rotations were more preferable compared to free rotations, but such a preference would depend on the specific purposes of applications. In addition, many studies have adopted a standard convention with regard to the positive and negative angles of rotation, with the former and the latter denoting a clockwise and an anticlockwise rotation, respectively [6]. However, such a convention was not examined per se in this study.

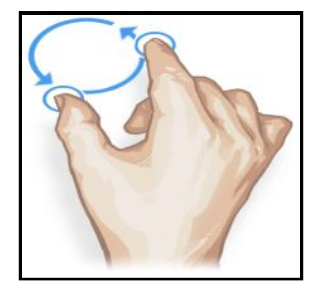

Figure 1. Free rotate gesture

To develop an effective multi-touch screen design application, user experience (a critical factor that is closely associated with product quality) needs to be emphasised. As highlighted in many studies [17], user experience (UX) has a broad range of definitions, depending on the researchers' different interest, conceptual interpretations, perspectives, and research focuses. Albeit the diverse definitions, many scholars agree that user experience is a measure of user's interaction with a product, an application, or a system [18]. Surprisingly, some people think that user experience is a construct that is immeasurable and, thus, cannot be analysed. Hence, in this study, we modified and used the user experience questionnaire (UEQ) to measure the attributes of user experience of preschool children in using a new, novel mobile application that supports free rotate gestures. As the children were not able to answer the questionnaire by themselves, the researchers developed an observation form to record the attributes. In addition, the children were interviewed to elicit information of the same attributes to help verify the observation findings. The questionnaire items of the UEQ were designed to elicit respondents' feelings, impressions, and attitudes toward their experience in using such a novel screen design, which indirectly reflected their satisfaction with the use of such a product [19]. Furthermore, the questionnaire items helped measure all elements of user experience, such as attractiveness, dependability, efficiency, perspicuity, novelty, and stimulation [19]. Specifically, attractiveness refers to the overall impression of users on free rotate gesture, and dependability is concerned with user control of the free rotate gesture. Efficiency refers to the ease in performing tasks with the use of the free rotate gesture, while perspicuity is a measure of the product familiarity when using the free rotate gesture. Meanwhile, stimulation relates to the motivation of users in using such gesture. As such, the UEQ was deemed to be an appropriate research instrument, enabling the researchers to gather all aspects of user experience of the children in using free rotate gesture with a mobile application. 


\section{RESEARCH METHOD}

\subsection{SUBJECTS}

The research subjects of this study were 10 preschool children, aged 5 and 6 , who were ablebodied with good motor skills. They were recruited with the consents of their parents and the National Child Development Research Centre (NCDRC), UPSI.

\subsection{PROCEDURES}

The subjects were divided into two groups based on their age, with the first group consisting of 5 year olds, and the second group comprising 6 year olds. Both groups were given a mobile application entitled "Mari Belajar Bentuk" to help them learn about shapes. Video recording of these preschool children's behaviours was carried out while they were performing free-rotate gestures to interact with the virtual shapes displayed on the multi-touch screen. While recording, the researchers also used an observation form to record the children's behaviours.

\subsection{RESEARCH INSTRUMENTS}

The research instrument used in this study was an observation form consisting of user experience attributes.

\subsection{THE APPLICATION}

For this study, the "Mari Belajar Bentuk" mobile application was installed on an Android tablet (see Figure 2), with which the children used free rotate gestures to learn about shapes (see Figure $3)$.

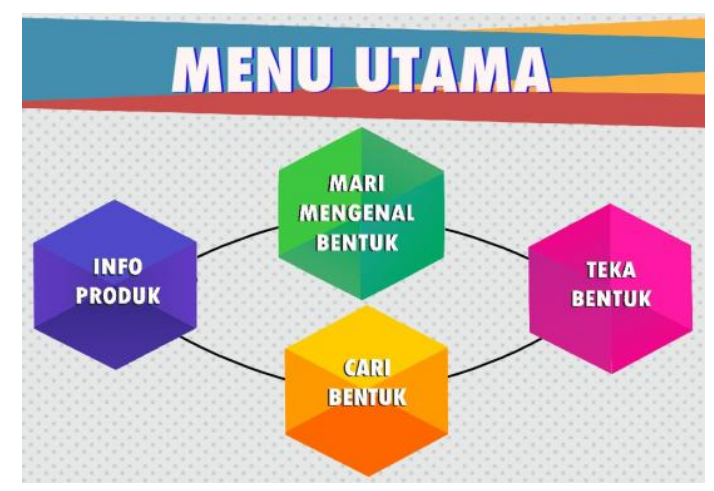

Figure 2. The main menu of the mobile application

\section{MARI BELANARBBEWHUK}

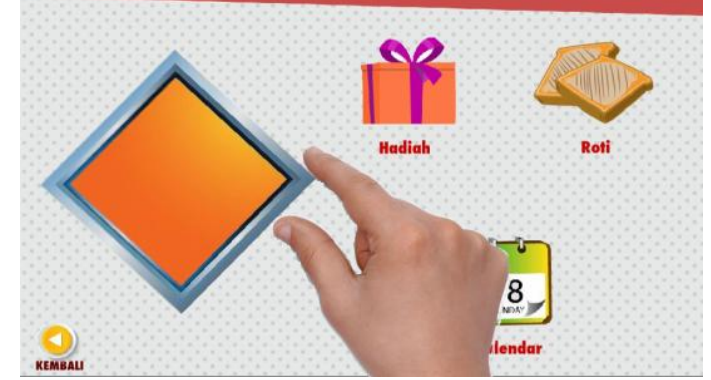

Figure 3. Interacting with shapes with free rotate gestures 
The International Journal of Multimedia \& Its Applications (IJMA) Vol.9, No.4/5/6, December 2017

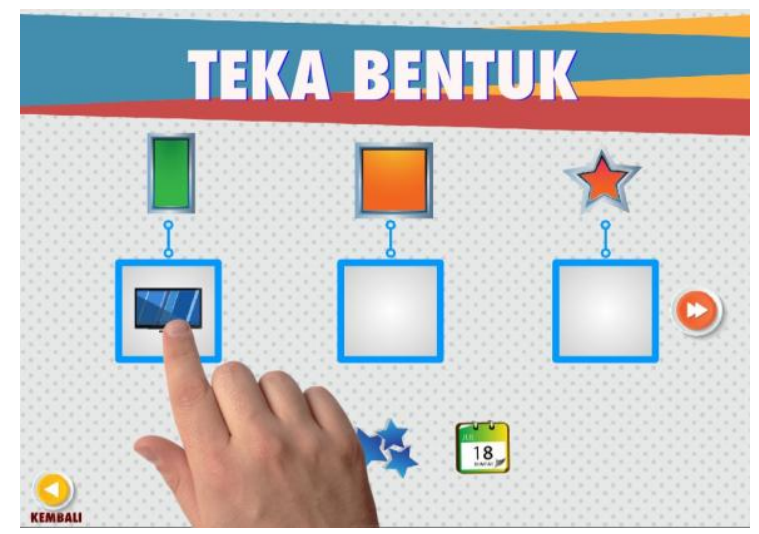

Figure 4. A student trying to guess a correct shape

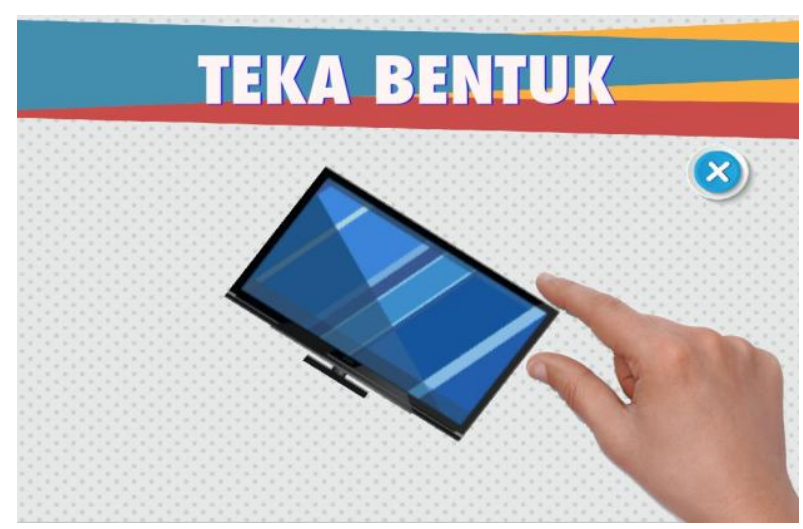

Figure 5. A student using free rotate gestures to interact with an object

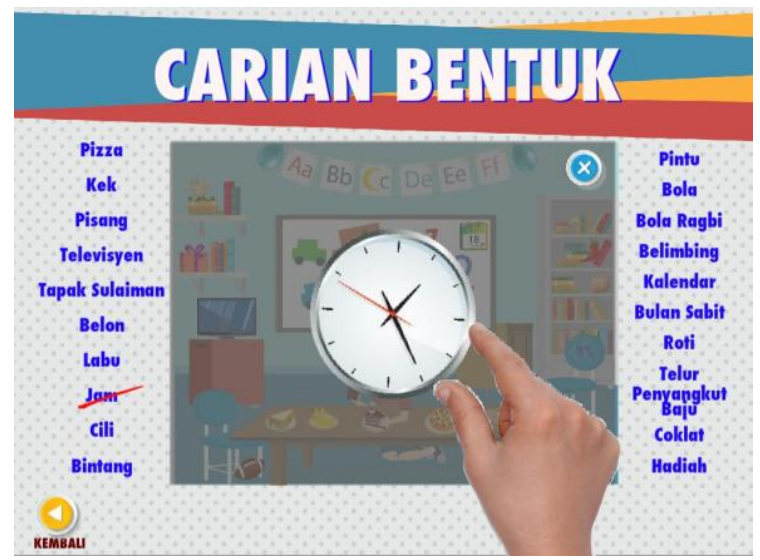

Figure 6. A student using free rotate gestures to find a shape

\section{RESUlt AND DiscUSSION}

The observations recorded in this study revealed several interesting findings pertaining to the attributes of user experience, such as attractiveness, dependability, efficiency, perspicuity, and stimulation. Table 1 and Table 2 summarize the findings of the attributes of user experience based on the observed learning behaviours of the five-year-old and six-year-old children. 
The International Journal of Multimedia \& Its Applications (IJMA) Vol.9, No.4/5/6, December 2017

Table 1. The observed behaviours of five-year-old preschool children in learning shapes using free rotate gestures

\begin{tabular}{|c|c|}
\hline $\begin{array}{c}\text { User } \\
\text { Experience } \\
\text { Attribute }\end{array}$ & Observation \\
\hline $\begin{array}{c}\text { Attractivene } \\
\text { ss }\end{array}$ & $\begin{array}{l}\text { - Child } 1 \text { was excited when using two fingers to rotate the shapes. } \\
\text { - Child } 2 \text { preferred to use several fingers to rotate the shapes. } \\
\text { - Child } 3 \text { was excited when using his fingers to rotate shapes and eager to } \\
\text { dabble with multi-touch screen design. } \\
\text { - Child } 4 \text { was attracted to multi-touch screen design, because he seemed } \\
\text { to love touching it with many of his fingers. } \\
\text { - Child } 5 \text { was highly excited as she used several fingers of both hands to } \\
\text { rotate the shapes. }\end{array}$ \\
\hline $\begin{array}{c}\text { Dependabilit } \\
\mathrm{y}\end{array}$ & $\begin{array}{l}\text { - Child } 1 \text { seemed familiar with the use of the multi-touch screen design. } \\
\text { - Child } 2 \text { looked more composed in using many fingers than that of using } \\
\text { only two fingers. } \\
\text { - Child } 3 \text { preferred to use two fingers to rotate the shapes. } \\
\text { - Child } 4 \text { looked comfortable in using several fingers to rotate the shapes } \\
\text { on the multi-touch screen design. } \\
\text { - Child } 5 \text { seemed confident in using many fingers to interact with the } \\
\text { shapes. }\end{array}$ \\
\hline Efficiency & $\begin{array}{l}\text { - Child } 1 \text { was a fast learner, as he only needed a brief demonstration to } \\
\text { learn to rotate the shapes. } \\
\text { - Child } 2 \text { was able to rotate the shapes by using several fingers without } \\
\text { any problems. } \\
\text { - Child } 3 \text { was able to rotate the shapes using many fingers and looked } \\
\text { comfortable to use the multi-touch screen design } \\
\text { - Child } 4 \text { had no problems using free-rotate gestures with his two index } \\
\text { fingers to rotate the shapes. } \\
\text { - Child } 5 \text { was able to rotate the shapes quite well, but she had to rely on } \\
\text { several fingers of both hands. }\end{array}$ \\
\hline Perspicuity & $\begin{array}{l}\text { - Child } 1 \text { seemed familiar with free-rotate gestures when using the } \\
\text { application. } \\
\text { - Child } 2 \text { could easily rotate the shapes, because she was familiar with the } \\
\text { use of the multi-touch finger gestures. } \\
\text { - Child } 3 \text { used several fingers to interact with the multi-touch screen } \\
\text { design. } \\
\text { - Child } 4 \text { frequently used many fingers to interact with the multi-touch } \\
\text { screen design. } \\
\text { - Child } 5 \text { seemed familiar with the use of free-rotate gestures when } \\
\text { interacting with the multi-touch screen design }\end{array}$ \\
\hline Stimulation & $\begin{array}{l}\text { - Child } 1 \text { looked highly interested and motivated in using the multi-touch } \\
\text { screen design. } \\
\text { - Child } 2 \text { was highly stimulated when using the application, indicating } \\
\text { that he would like to use it again. } \\
\text { - Child } 3 \text { quickly developed a strong fascination with the application after } \\
5 \text { minutes of using it. } \\
\text { - Child } 4 \text { was not interested in using this application. } \\
\text { - Child } 5 \text { was keen to continue playing with the multi-touch screen } \\
\text { design. }\end{array}$ \\
\hline
\end{tabular}


The International Journal of Multimedia \& Its Applications (IJMA) Vol.9, No.4/5/6, December 2017

Table 2. The observed behaviours of six-year-old preschool children in learning shapes using free rotate gestures

\begin{tabular}{|c|c|}
\hline $\begin{array}{c}\text { User } \\
\text { Experience } \\
\text { Attributes }\end{array}$ & Observation \\
\hline $\begin{array}{l}\text { Attractiven } \\
\quad \text { ess }\end{array}$ & $\begin{array}{l}\text { - Child } 1 \text { loved to use many of his fingers to rotate the shapes. } \\
\text { - Child } 2 \text { was very excited to use the multi-touch screen design and knew } \\
\text { how to rotate the shapes. } \\
\text { - Child } 3 \text { preferred multi-finger hand gestures to rotate the shapes. } \\
\text { - Child } 4 \text { was captivated by the use of multi-touch finger gestures. } \\
\text { - Child } 5 \text { loved to rotate the shapes quickly, as the multi-touch screen } \\
\text { design seemed appealing to him. }\end{array}$ \\
\hline $\begin{array}{l}\text { Dependabil } \\
\text { ity }\end{array}$ & $\begin{array}{l}\text { - Child } 1 \text { was comfortable to use many fingers to rotate the shapes on the } \\
\text { multi-touch screen design } \\
\text { - Child } 2 \text { knew how to rotate the shapes but seemed to struggle to control } \\
\text { the movements of his finger } \\
\text { - Child } 3 \text { looked happy to rotate the shapes on the multi-touch screen } \\
\text { design. } \\
\text { - Child } 4 \text { liked to control the finger movements on the multi-touch screen } \\
\text { design. } \\
\text { - Child } 5 \text { had some difficulties initially, but later he managed to interact } \\
\text { with the shapes on multi-touch screen design quite naturally. }\end{array}$ \\
\hline Efficiency & $\begin{array}{l}\text { - Child } 1 \text { had no difficulties to follow the instructions to rotate the } \\
\text { shapes. } \\
\text { - Child } 2 \text { did not find rotating the shapes using free-rotate gestures to be } \\
\text { daunting. } \\
\text { - Child } 3 \text { had no difficulties to rotate the shapes using many of his } \\
\text { fingers. } \\
\text { - Child } 4 \text { was able to rotate the shapes, as he was familiar with such } \\
\text { computer game. } \\
\text { - Child } 5 \text { had some difficulties initially, but later he managed to rotate the } \\
\text { shapes on multi-touch screen design quite comfortably. }\end{array}$ \\
\hline Perspicuity & $\begin{array}{l}\text { - Child } 1 \text { seemed familiar with multi-finger interactions of the multi- } \\
\text { touch screen design. } \\
\text { - Child } 2 \text { used many of his fingers to interact with the multi-touch screen } \\
\text { design. } \\
\text { - Child } 3 \text { had the tendency to try to use many of his fingers when } \\
\text { handling the application. } \\
\text { - Child } 4 \text { looked familiar with the use of the multi-touch screen design. } \\
\text { the shild } 5 \text { looked confident in using many of his fingers to interact with }\end{array}$ \\
\hline Stimulation & $\begin{array}{l}\text { - Child } 1 \text { was not interested to continue using the computer game, as he } \\
\text { seemed more interested in performing other physical activities. } \\
\text { - Child } 2 \text { was extremely excited to use the computer game. } \\
\text { - Child } 3 \text { was not interested to continue using the computer game. } \\
\text { - Child } 4 \text { had to stop using the computer game halfway due to health } \\
\text { reasons. } \\
\text { - Child } 5 \text { indicated he was interested to continue using the computer } \\
\text { game in the future. }\end{array}$ \\
\hline
\end{tabular}


The findings showed that almost all the preschool children, despite being young (aged 5 and 6), were able to apply free rotate gestures on the touchscreen with ease. In particular, they were also observed to be highly excited to use their fingers, with some using two fingers and others using more than two fingers of both of their hands, in manipulating or rotating all the shapes of the application. This finding suggest that the attractiveness of the mobile application is high, making it appealing to users. Likewise, a similar positive finding for the dependability of the mobile application was also observed. Seemingly, the preschool children were able to use the application without any problems. In fact, they were able to follow all the instructions that helped them perform all the tasks of the application quickly and easily. Such finding was evidenced by their ability to apply free rotate gestures to the touchscreen dextrously.

In terms of efficiency, a majority of the preschool children could perform all the tasks (rotating the shapes displayed on the touchscreen by gesturing with their fingers). Presumably, these children were fast learners. Nonetheless, a minority of the children required some assistance before they could perform such tasks. Overall, the ability of these children in performing all the tasks seemed natural, suggesting that the efficiency of the mobile application is quite impressive. Interestingly, all the preschool children were observed to be familiar with the touchscreen technology. As such, the perspicuity of the mobile device can be reasonably deemed to be high. Similarly, the stimulation aspect of the mobile application is deemed high, given that the children were observed to be highly engaged and extremely motivated when performing the tasks of manipulating shapes.

Additionally, the duration of performing the tasks of manipulating shapes was emphasized and examined. The observations recorded in the video showed that most children paid close attention to completing the tasks given. Initially, they used only one finger to rotate the shapes. Then, after several minutes, they began using more of their fingers to manipulate the shapes. Finally, after 5 minutes, the children were observed to be dextrous in rotating such shapes to the extent that they managed to complete the task quickly. In addition, the observations showed another positive trait of the children, indicating that they were attentive and well-disciplined. Nonetheless, a few of them seemed to lack focus and diligence, as attested by their inability to complete the tasks on time. Overall, the above findings strongly suggest that the user experience of young users in using free rotate gestures with such mobile application is high, which can help them to learn about shapes more effectively.

\section{Conclusions}

The overall finding of this study strongly suggests that free rotate gestures on multi-touch screen design can enhance preschool children's user experience (UX) in learning shapes. With high user experience in using mobile applications, young children can experience engaging and meaningful learning as they interact with learning contents by simply touching and gesturing the touchscreen almost effortlessly. Such interactions are not only natural but also enjoyable, the impact of which makes students become highly motivated. Given that this study only examined interactions based on free rotate gestures, future research should focus on the impact of multi-touch screen design on learning achievements of preschool children.

\section{REFERENCES}

[1] Hussain, N. H., Wook, T. S. M. T., Noor, S. F. M., \& Mohamed, H. (2016). Children's interaction ability towards multi-touch gestures. International Journal on Advanced Science, Engineering and Information Technology, 6(6), 875-881.

[2] Walker, D. What's New In Multi Touch Technology?. Retrieved April, 20, 2017, from http://citeseerx.ist.psu.edu/viewdoc/download?doi=10.1.1.736.9394\&rep=rep1\&type=pdf 
[3] Sulaiman, S., Mahmood, A. K., \& Khan, M. (2015, January). Investigation of fingertip contact area and shape for precise target selection on multi-touch screen. In Proceedings of the 9th International Conference on Ubiquitous Information Management and Communication (p. 31). ACM.

[4] Nacher, V., Jaen, J., Navarro, E., Catala, A., \& González, P. (2015). Multi-touch gestures for prekindergarten children. International Journal of Human-Computer Studies, 73, 37-51.

[5] Hoggan, E., Williamson, J., Oulasvirta, A., Nacenta, M., Kristensson, P. O., \& Lehtiö, A. (2013, April). Multi-touch rotation gestures: Performance and ergonomics. In Proceedings of the SIGCHI Conference on Human Factors in Computing Systems - CHI 13, 3047-3050.

[6] Nimbarte, M. (2011). Multi-touch screen interfaces and gestures analysis: A study. Advanced Computing, 2(6), 113.

[7] McKenney, S., \& Voogt, J. (2010). Technology and young children: How 4-7 year olds perceive their own use of computers. Computers in Human Behavior, 26(4), 656-664.

[8] Aziz, N. A. A. (2013). Children's interaction with tablet applications: Gestures and interface design. Children, 2(3), 447-450.

[9] Radich, J. (2013). Technology and interactive media as tools in early childhood programs serving children from birth through age 8. Every Child, 19(4), 18.

[10] Verenikina, I., \& Kervin, L. (2011). iPads, digital play and pre-schoolers. He Kupu, 2(5), 4-19.

[11] Genc, Z. (2014). Parents' perceptions about the mobile technology use of preschool aged children. Procedia-Social and Behavioral Sciences, 146, 55-60.

[12] Blackwell, C. (2013). Teacher practices with mobile technology: integrating tablet computers into the early childhood classroom. Journal of Education Research, 7(4), 1-25.

[13] Dauksas, L., \& White, J. (2014). Discovering Shapes and Space in Preschool. Teaching Young Children, 7(4), 22-26.

[14] Shape and Space. (2012, October 17). Retrieved April, 20, 2017, from https://www.earlychildhoodireland.ie/shape-and-space/

[15] Hancock, M. S., Vernier, F. D., Wigdor, D., Carpendale, S., \& Shen, C. (2006, January). Rotation and translation mechanisms for tabletop interaction. In Horizontal Interactive Human-Computer Systems, 2006. TableTop 2006. First IEEE International Workshop on, 8.

[16] Kruger, R., Carpendale, S., Scott, S. D., \& Tang, A. (2005, April). Fluid integration of rotation and translation. In Proceedings of the SIGCHI conference on Human factors in computing systems, 601610 .

\section{AUTHORS}

Fadhlina Mohd Razali is a lecturer at the Faculty of Art, Computing, and Creative Industry, Sultan Idris Education University. Her research interest is in Child-Computer Interaction, Multimedia Application Development, Gestural Interface Design, Gamification and Early Childhood Education.

Nor Azah Abd Aziz is an associate professor at the Faculty of Art, Computing and Creative Industry, Sultan Idris Education University. Her research interest is in Gestural Interface Design, Child Computer Interaction, Multimedia Application Development, Islamic Spiritual Psychology, Information Technology, Internet / Web Filtering and Internet and Society.
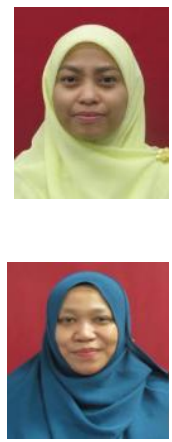
The International Journal of Multimedia \& Its Applications (IJMA) Vol.9, No.4/5/6, December 2017

Siti Aisyah Salim is a senior lecturer at the Faculty of Art, Computing, and Creative Industry, Sultan Idris Education University. Her research interest is in Knowledge Management, Database Management, Enterprise System, Cloud ERP, Innovation Adoption, Organisational Decision Making, and Multi-group.

Mohamad Rasli is a lecturer at the Faculty of Art, Computing and Creative Industry, Sultan Idris Education University. Her research interest is in Artificial Intelligence, Intelligent System, Data Mining/Knowledge Discovery in Databases, Neural Network, Robotics, Natural Language Processing, and Multimedia Interactive.

Nur Farah Zulkefly is a research assistant at the Faculty of Art, Computing and Creative Industry, Sultan Idris Education University. Her research interest is in Information Security Assurance, Information Management System, Gestural Interface Design, and Gamification. 